\title{
PELAKSANAAN PATIENT SAFETY DI RUMAH SAKIT UMUM DAERAH DAN RUMAH SAKIT UMUM SWASTA BANTUL BERDASARKAN KETENTUAN UNDANG-UNDANG NOMOR 44 TAHUN 2009 TENTANG RUMAH SAKIT
}

\author{
IMPLEMENTATION OF PATIENT SAFETY IN GENERAL HOSPITAL \\ REGIONAL GENERAL HOSPITAL AND PRIVATE BANTUL PROVISION OF \\ LAW NUMBER 44 OF 2009 CONCERNING THE HOSPITAL
}

\author{
Yuni Fitriana ${ }^{1}$, Kurniasari Pratiwi $^{2}$
}

\author{
${ }^{1,2}$ Akademi Kebidanan Yogyakarta
}

Keselamatan pasien sebagai suatu sistem memberikan asuhan kepada pasien lebih aman, mencegah cedera akibat kesalahan karena melakukan tindakan atau tidak melakukan tindakan yang seharusnya dilakukan. Insiden keselamatan pasien meliputi kesalahan medis (medical errors), kejadian yang tidak diharapkan (adverse event), dan nyaris terjadi (near miss). Undang-undang Nomor 44 Tahun 2009 tentang Rumah Sakit bertujuan memberikan perlindungan kepada pasien, masyarakat, dan sumber daya manusia, mempertahankan dan meningkatkan mutu pelayanan rumah sakit, serta memberi kepastian hukum kepada masyarakat dan rumah sakit. Program Sasaran Keselamatan Pasien mengacu pada Nine Saving Safety Solution. Mengetahui perbedaan Pelaksanaan Patient Safety Di RSUD Dan RSU Swasta Bantul Berdasarkan Ketentuan Undang-Undang Nomor 44 Tahun 2009 Tentang Rumah Sakit, serta cara mengatasi. Jenis penelitian kuantitatif, metode pendekatan analitik komparatif. Sample penelitian sebanyak 40 orang dengan teknik total sample dan simple random sample. Alat instrumen dengan kuesioner dan indept interview meliputi nine saving safety solution. Analisa data secara univariat dan bivariat dengan menggunakan uji T-independent wilcoxon.Sebagian besar pelaksanaan patient safety di RSUD dan RSU Swasta Bantul dalam kategori baik yaitu sebanyak 22 (55,0\%) dan 26 (65,0\%). Tidak terdapat perbedaan pelaksanaan patient safety di RSUD dan RSU Swasta Bantul, dengan uji wilcoxon nilai probabilitas sebesar 0,475 ( $\alpha>0,05)$. Cara mengatasi hambatan dalam pelaksanaan patient safety perlu adanya pelatihan bagi Tenaga kesehatan secara berkala berkaitan dengan patient safety, adanya kerjasama dari berbagai pihak di rumah sakit serta sarana dan prasarana penunjang juga harus dilengkapi agar pelaksanaan patient safety dapat berjalan dengan baik

Kata kunci : Keselamatan pasien, Tenaga 


\begin{abstract}
Patient safety as a system of giving care to patients safer, prevent injury due to errors due to any action or inaction that should be done. Patient safety incidents include medical error (medical errors), unexpected events (adverse event), and near misses (near miss). Hospital aims to provide protection to patients, society, and human resources, maintain and improve the quality of hospital services, as well as provide legal certainty to the community and the hospital. Patient Safety Goal Program refers to the Nine Saving Safety Solution. To know the difference Implementing Patient Safety At Bantul Hospital and Private Hospital Based on provisions of Law Number 44, 2009 About the Hospital. Quantitative research, comparative analytic approach. Sample study of 40 people with a total samples and simple random sample. Instrument with a questionnaire and interview indept include a nine saving safety solution. The data analysis univariate and bivariate using $T$-independent test of Wilcoxon. Most of the implementation of patient safety in hospitals of Bantul in both categories as many as 22 ( $55.0 \%)$ and $26(65.0 \%)$. There were no differences in the implementation of patient safety in hospitals and private hospital Bantul. How to overcome obstacles in the implementation of patient safety need for training for health workers on a regular basis with regard to patient safety, the cooperation of various parties in the hospital as well as the supporting infrastructures must also be fitted so that the implementation of patient safety can run well
\end{abstract}

Keywords : Patient safety, medical personnel 


\section{PENDAHULUAN}

\begin{tabular}{lcr}
\multicolumn{2}{c}{ rumah sakit } & sebagai tempat \\
penyelenggaraan & pelayanan \\
kesehatan & yang & bersifat \\
penyembuhan & (kuratif) & dan \\
pemulihan & (rehabilitative)
\end{tabular} mempunyai potensi yang besar dalam penularan atau penyebaran penyakit, baik dari pasien ke tenaga kesehatan atau sebaliknya, dari pasien ke alat/fasilitas kesehatan atau sebaliknya, dan dari tenaga kesehatan ke alat/fasilitas kesehatan.

Rumah sakit dalam melaksanakan tujuan, fungsi dan perannya memerlukan suatu bentuk pengaturannya yang jelas. Banyak unsur-unsur yang terkandung di dalam penyelenggaraan Rumah Sakit terutama terkait dengan tugas utamanya dalam pelayanan publik yakni melakukan pelayanan kesehatan, maka membutuhkan perangkat hukum yang memadai. Hal itu dimaksudkan agar penyelenggaraannya sungguhsungguh dapat sesuai dengan kedudukan, peran dan fungsinya, serta terutama untuk dapat memenuhi amanat konstitusi yaitu mewujudkan kesejahteraan masyarakat.

$$
\text { Berdasarkan tujuan }
$$

penyelenggaraan pelayanan rumah sakit yang tercantum dalam UndangUndang Republik Indonesia Nomor 44 tahun 2009 tentang Rumah Sakit (selanjutnya disingkat UURS) pada Pasal 3 yaitu a. mempermudah akses masyarakat untuk mendapatkan pelayanan kesehatan, b. memberikan perlindungan terhadap keselamatan pasien, masyarakat, lingkungan rumah sakit dan sumber daya manusia di rumah sakit, c. meningkatkan mutu dan mempertahankan standar pelayanan rumah sakit, dan d. memberikan kepastian hukum kepada pasien, masyarakat, sumber daya manusia rumah sakit dan rumah sakit.

Makna undang-undang tersebut di atas bahwa rumah sakit memiliki tugas utama yaitu memberikan pelayanan kesehatan dengan memberikan perlindungan kepada semua pihak terutama perlindungan kepada pasien. Setiap pasien di rumah sakit tentu membutuhkan jaminan keamanan, terutama dalam penanganan kesehatannya. Untuk itu diperlukan standar penanganan agar jangan sampai terjadi tindakan di luar standar penanganan pasien yang ujungnya justru membahayakan kehidupan pasien rumah sakit.

Kesalahan dalam penanganan pasien yang justru merugikan pasien sejauh mungkin harus dihindari, baik yang dilakukan oleh dokter, perawat serta petugas rumah sakit lain. Untuk itu pasien dan keluarganya membutuhkan suatu jaminan hukum bagi penanganan petugas rumah sakit. Sehingga hal-hal penanganan pasien di luar standar sejauh mungkin bisa dihindarkan. (Wahyati, 2012)

Organisasi kesehatan dunia WHO (World Health Organization) juga telah menegaskan pentingnya Keselamatan dalam pelayanan kepada pasien: "Safety is a fundamental principle of patient care and a critical component of quality management." Sehubungan dengan data Kejadian Tidak Diharapkan (KTD) di Rumah Sakit di berbagai negara menunjukkan angka: $3-16 \%$ yang tidak kecil. (WHO. 2004)

Di rumah sakit terdapat ratusan macam obat, ratusan tes dan 
prosedur, banyak alat dengan teknologinya, bermacam jenis tenaga profesi dan non profesi yang siap memberikan pelayanan pasien 24 jam terus menerus. Keberagaman dan kerutinan pelayanan tersebut apabila tidak dikelola dengan baik dapat terjadi KTD.(Depkes RI, 2006)

Pada tahun 2000 Institute of

Medicine di Amerika Serikat menerbitkan laporan yang mengagetkan banyak pihak : "TO ERR IS HUMAN", Building a Safer Health System. Laporan itu mengemukakan penelitian di rumah sakit di Utah dan Colorado serta New York. Di Utah dan Colorado ditemukan KTD (Adverse Event) sebesar 2,9 \%, dimana $6,6 \%$ diantaranya meninggal. Sedangkan di New York KTD adalah sebesar 3,7 $\%$ dengan angka kematian 13,6 \%. Angka kematian akibat KTD pada pasien rawat inap di seluruh Amerika yang berjumlah 33,6 juta per tahun berkisar 44.000 - 98.000 per tahun. Publikasi WHO pada tahun 2004, mengumpulkan angka-angka penelitian rumah sakit di berbagai Negara : Amerika, Inggris, Denmark, dan Australia, ditemukan KTD dengan rentang $3,2-16,6 \%$. Dengan data-data tersebut, berbagai negara segera melakukan penelitian dan mengembangkan Sistem Keselamatan Pasien. (Linda, 2005)

Di Indonesia data tentang KTD apalagi Kejadian Nyaris Cedera (Near miss) masih langka, namun dilain pihak terjadi peningkatan tuduhan "malpraktek", yang belum tentu sesuai dengan pembuktian akhir. Dalam rangka meningkatkan keselamatan pasien di rumah sakit maka Perhimpunan Rumah Sakit Seluruh Indonesia (PERSI) telah mengambil inisiatif membentuk Komite Keselamatan Pasien Rumah Sakit (KKPRS) pada tanggal 1 Juni 2005. Komite tersebut telah aktif melaksanakan langkah langkah persiapan pelaksanaan keselamatan pasien rumah sakit dengan mengembangkan laboratorium program keselamatan pasien rumah sakit. Selanjutnya Gerakan Keselamatan Pasien Rumah Sakit ini kemudian dicanangkan oleh Menteri Kesehatan pada Seminar Nasional PERSI pada tanggal 21 Agustus 2005, di Jakarta Convention Centre Jakarta.(KPP-RS, 2012)

KKPRS telah menyusun Panduan sembilan Langkah Menuju Keselamatan Pasien untuk mengimplementasikan Keselamatan Pasien di rumah sakit. Di samping itu pula KARS (Komite Akreditasi Rumah Sakit) Departemen Kesehatan telah menyusun Standar Keselamatan Pasien Rumah Sakit yang akan menjadi salah satu Standar Akreditasi. (KPP-RS, 2012)

$$
\text { Mengingat keselamatan }
$$
pasien sudah menjadi tuntutan masyarakat maka pelaksanaan program keselamatan pasien rumah sakit perlu dilakukan. Berkaitan dengan tuntutan keselamatan pasien tersebut maka diperlukan acuan yang jelas untuk melaksanakan keselamatan pasien tersebut. Buku Panduan Nasional Keselamatan Pasien Rumah Sakit yang terutama berisi Standar Keselamatan Pasien Rumah Sakit dan Tujuh Langkah Menuju Keselamatan Pasien Rumah Sakit diharapkan dapat membantu rumah sakit dalam melaksanakan kegiatannya.(Depkes RI, 2006)

Keselamatan pasien sebagai suatu sistem diharapkan memberikan 
asuhan kepada pasien lebih aman, mencegah cedera akibat kesalahan karena melakukan tindakan atau tidak melakukan tindakan yang seharusnya dilakukan. Keselamatan pasien juga merupakan suatu sistem dimana rumah sakit membuat asuhan pasien lebih aman. Sistem tersebut meliputi penilaian risiko, identifikasi pasien, resiko pasien terjatuh, pengelolaan hal yang berhubungan dengan pasien koma, pelaporan dan analisis accident, kemampuan belajar dari accident dan tindak lanjutnya serta implementasi solusi untuk meminimalkan timbulnya risiko.(Cahyono,2008)

$$
\text { Program }
$$

Sasaran

Keselamatan Pasien mengacu pada Nine Saving Safety Solution dari WHO Patient Safety 2007 yang digunakan oleh Komite Keselamatan Pasien RS PERSI (KKPRS PERSI), dan dari JCI yang merupakan badan dunia yang pertama kali terakreditasi oleh International Standar Quality yang menjadikan sasaran keselamatan pasien menjadi salah satu tolak ukur dalam akreditasi.

Rumah Sakit Umum Daerah Panembahan Senopati Batul yang berdiri sejak tahun 1953 yang semula bernama Rumah Sakit Hongeroedem. Pada tahun 2003 berubah nama dengan Rumah Sakit Umum Daerah Panembahan Senopati Batul (RSUD Panembahan Senopati) yang merupakan salah satu Rumah Sakit Pemerintah yang representative mewakili gambaran Rumah Sakit yang ada di Kabupaten Bantul. Rumah Sakit ini memberikan pelayanan komprehensif meliputi upaya kesehatan yang bersifat promotif, preventif, kuratif dan rehabilitatif, dengan jangkauan pelayanan luas hingga ke lapisan masyarakat tingkat bawah. Di samping itu keterbukaan dan dukungan dari pihak manajemen Rumah Sakit serta komitmen para staffnya sangat besar untuk menerapkan tindakan medis dalam pelayanan kepada masyarakat mengacu pada keselamatan pasien. Hasil wawancara pada bidang keperawatan bahwa tenaga medis di RSUD Panembahan Senopati telah mendapatkan pelatihan budaya keselamatan pasien meski dalam pelaksanaannya masih belum sempurna karena pemahaman yang masih berbeda-beda. Pada tahun 2014 terdapat 22 kejadian dari pasien Rawat Inap mengalami kejadian seperti kesalahan tindakan medis (near miss), Kejadian Tidak Diinginkan (KTD), dan Kejadian Nyaris Cedera (KNC) serta sentinel. Peneliti melakukan pengamatan sesaat serta menemukan beberapa hal seperti fasilitas-fasilitas pendukung rumah sakit seperti penggunaan kamar mandi yang tidak steril, terkesan kotor dan licin sehingga memungkinkan mudahnya pasien tertularnya oleh penyakit-penyakit lain ataupun resiko terjatuh, serta jalan menuju Instalasi Gawat Darurat (IGD) yang landai sehingga resiko terpeleset. Beberapa kondisi di atas sebenarnya sudah menunjukkan adanya perhatian yang rendah terhadap keselamatan pasien.

Rumah Sakit Rajawali Citra (RSRC) terletak di Pleret KM 25 Banjardadap, Potorono, Banguntapan, Bantul Yogyakarta yang dibangun pada tahun 2008. RSRC merupakan rumah sakit milik yayasan swasta dengan tipe D. 
Rumah sakit ini bersifat transisi dengan kemampuan hanya memberikan pelayanan kedokteran umum dan gigi. Rumah sakit ini juga menampung rujukan yang berasal dari puskesmas. Rumah Sakit ini Berukuran sedang, tempat ini tersedia 50 tempat tidur inap, kurang lebih sama dibanding setiap rumah sakit di Yogyakarta yang tersedia rata-rata 50 tempat tidur inap. Jumlah Dokter Tersedia 23 dokter, rumah sakit ini tersedia lebih sedikit dibanding rata-rata rumah sakit di Yogyakarta. Pelayanan Rawat Inap termasuk kelas menengah, serta 5 dari 50 tempat tidur di rumah sakit ini berkelas VIP keatas.

RSRC telah melaksanakan patient safety, keselamatan pasien dilakukan oleh tenaga kesehatan yang telah mendapatkan pelatihan sebelumnya. Berdasarkan hasil wawancara diperoleh data bahwa pelaksanaan patient safety ini belum optimal karena persepsi tentang hal ini berbeda-beda, namun pihak rumah sakit sangat mendukung pelaksanaan keselamatan pasien ini dengan baik sesuai standar keselamatan pasien yang berlaku. Adapun kejadian yang tidak diinginkan yang terjadi dalam pelayanan kesehatan di rumah sakit ini dan telah dalam proses pelaporan untuk dapat ditindak lanjuti. Insiden kejadian yang tidak diinginkan dari tahun ketahun menunjukkan penurunan, pada tahun 2012 terdapat 20 insiden, tahun 2013 terdapat 7 insiden, dan pada tahun 2014 terdapat 4 insiden.

Insiden yang terjadi berupa pengunjung terpeleset karena lantai licin, dokter salah tulis resep obat, resep tanpa atura pakai, pasien terjatuh dari tempat tidur, kesalahan penyerahan obat kepada pasien yang salah, salah tulis identitas pasien, pengukuran tanda-tanda vital dengan alat yang rusak, keterlambatan penggatian cairan infuse, pengantar untuk radiologi salah penulisan dan tidak ada diagnose klinis, luka tergores karena kaca jendela yang melorot, pasien terjebak dikamar mandi, kesalahan pemberian nama yang tidak sesuai antara rekam medis dengan resep obat pasien, serta komunikasi antara tenaga medis dengan pasien/keluarga yang tidak jelas sehingga terjadi kesalahan persepsi.

Berdasarkan hal tersebut di atas maka penulis tertarik untuk melakukan penelitian yang bertujuan untuk mengetahui pelaksanaan patient safety di Rumah Sakit Umum Daerah Bantul, mengetahui pelaksanaan patient safety di Rumah Sakit Umum Swasta Bantul dan membandingkan pelaksanaan patient safety di Rumah Sakit Umum Daerah Dan Rumah Sakit Umum Swasta Bantul

\section{METODE PENELITIAN}

Penelitian ini merupakan jenis penelitian kuantitatif dengan menggunakan metode pendekatan perbandingan analitik (analisis comparation). Penelitian ini untuk menggambarkan perbedaan pelaksanaan patient safety di rumah sakit umum daerah dengan rumah sakit swasta berkaitan tentang nine saving safety solution. Pendekatan penelitian menggunakan studi cross sectional (Notoatmodjo, 2003).

Populasi dalam penelitian ini adalah perawat atau bidan yang bekerja di Rumah Sakit Umum 
Daerah Panembahan Senopati Bantul dan Rumah Sakit Umum Swasta Rajawali Citra Bantul pada bangsal rawat inap. Perawat atau bidan di Rumah Sakit Umum Daerah Panembahan Senopati Bantul pada bangsal rawat inap sebanyak 187 orang dan Rumah Sakit Umum Swasta Rajawali Citra Bantul pada bangsal rawat inap sebanyak 40 orang, untuk mendapatkan perbandingan yang seimbang maka sampel yang digunakan adalah 40 orang.

Teknik sampling yang digunakan pada penelitian ini adalah total sample pada responden rumah sakit Rajawali Citra, sedangkan teknik sampling yang digunakan untuk sampel rumah sakit umum daerah panembahan senopati yaitu simple random sampling

Penelitian ini menggunakan kuesioner/ angket sebagai alat pengumpulan data berdasarkan panduan nasional keselamatan pasien (Patient Safety) yang disusun oleh Komite Akreditasi Rumah Sakit Departemen Kesehatan. Kuesioner berisi daftar pertanyaan berjumlah 9 item total pernyataan 45 . Pernyataan mengacu pada Sembilan solusi keselamatan pasien (nine saving safety Solution) yaitu :

1. Perhatikan Nama Obat, Rupa dan Ucapan Mirip (Look-Alike, Sound-Alike Medication Names).

2. Pastikan Identifikasi Pasien.

3. Komunikasi Secara Benar saat Serah Terima / Pengoperan Pasien.

4. Pastikan Tindakan yang benar pada Sisi Tubuh yang benar.

5. Kendalikan Cairan Elektrolit Pekat (Concentrated).

6. Pastikan Akurasi Pemberian Obat pada Pengalihan Pelayanan.

7. Hindari Salah Kateter dan Salah Sambung Slang (Tube).

8. Gunakan Alat Injeksi Sekali Pakai.

9. Tingkatkan Kebersihan Tangan (Hand Hygiene) untuk Pencegahan Infeksi Nosokomial

Analisa data tersebut meliputi analisis univariat dan analisis bivariat (Notoatmodjo, 2003). Analisis bivariat menggunakan uji statistik yang digunakan Uji T- Independent. Uji T- Independent digunakan untuk menguji perbedaan pada dua kelompok yang independent (saling bebas). Data dilakukan uji normalitas data dengan Shapiro Wilk.

\section{A. Hasil dan Pembahasan}

1. Keselamatan Pasien di RSUD Bantul

Tabel 1. Jawaban Tiap Item Keselamatan Pasien di RSUD Bantul

\begin{tabular}{|c|c|c|c|c|c|}
\hline \multirow{2}{*}{ No } & \multirow{2}{*}{ Pernyataan } & \multicolumn{2}{|c|}{ Tidak baik } & \multicolumn{2}{|c|}{ Baik } \\
\hline & & $\mathrm{n}$ & $\%$ & $\mathrm{n}$ & $\%$ \\
\hline A & $\begin{array}{l}\text { Perhatian nama obat, rupa dan ucapan mirip } \\
\text { (look alike, sound-alike medication names) }\end{array}$ & 18 & 45.0 & 22 & 55.0 \\
\hline B & Pasrikan identifikasi pasien & 9 & 22.5 & 31 & 77.5 \\
\hline $\mathrm{C}$ & $\begin{array}{l}\text { Komunikasi secara benar saat serah terima } \\
\text { pasien }\end{array}$ & 11 & 27.5 & 29 & 72.5 \\
\hline $\mathrm{D}$ & $\begin{array}{l}\text { Pastikan tindakan yang benar pada sisi tubuh } \\
\text { yang benar }\end{array}$ & 6 & 15.0 & 34 & 85.0 \\
\hline $\mathrm{E}$ & Kendalikan cairan elektrolit pekat & 14 & 35.0 & 26 & 65.0 \\
\hline $\mathrm{F}$ & $\begin{array}{l}\text { Pastikan akurasi pemberian obat pada } \\
\text { pengalihan pelayanan }\end{array}$ & 13 & 32.5 & 27 & 67.5 \\
\hline
\end{tabular}




\begin{tabular}{llllll} 
G & Hindari salah kateter dan salah sambung slang & 15 & 37.5 & 25 & 62.5 \\
H & Gunakan alat injeksi sekali pakai & 13 & 32.5 & 27 & 67.5 \\
I & $\begin{array}{l}\text { Tindakan kebersihan tangan untuk pencegahan } \\
\text { infeksi nosokomial }\end{array}$ & 2 & 5.0 & 38 & 95.0 \\
\hline
\end{tabular}

Berdasarkan item keselamatan pasien di RSUD Bantul responden yang menjawab baik paling banyak ada di item pernyataan tindakan kebersihan tangan untuk pencegahan infeksi nosocomial yaitu sebanyak 38 responden. Sedangkan responden yang menjawab tidak baik paling banyak ada di pernyataan perhatian nama obat, rupa dan ucapan mirip (look alike, sound-alike medication names) yaitu sebanyak 18 responden.

Tabel 2. Keselamatan Pasien di RSUD Bantul

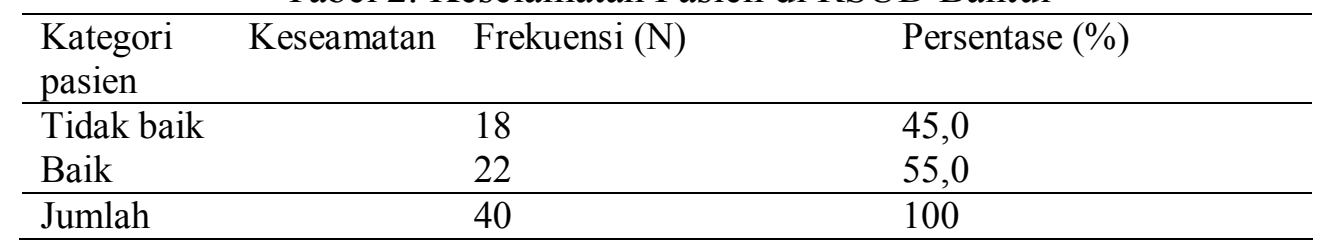

2. Keselamatan Pasien di Rumah Sakit Umum Swasta Bantul Tabel 3. Jawaban Tiap Item Keselamatan Pasien di RSU Swasta Bantul

\begin{tabular}{|c|c|c|c|c|c|}
\hline \multirow{2}{*}{ No } & \multirow{2}{*}{ Pernyataan } & \multicolumn{2}{|c|}{ Tidak baik } & \multicolumn{2}{|c|}{ Baik } \\
\hline & & $\mathrm{n}$ & $\%$ & $\mathrm{n}$ & $\%$ \\
\hline A & $\begin{array}{l}\text { Perhatian nama obat, rupa dan ucapan mirip } \\
\text { (look alike, sound-alike medication names) }\end{array}$ & 6 & 15.0 & 34 & 85.0 \\
\hline B & Pastikan identifikasi pasien & 19 & 47.5 & 21 & 52.5 \\
\hline $\mathrm{C}$ & $\begin{array}{l}\text { Komunikasi secara benar saat serah terima } \\
\text { pasien }\end{array}$ & 9 & 22.5 & 31 & 77.5 \\
\hline $\mathrm{D}$ & $\begin{array}{l}\text { Pastikan tindakan yang benar pada sisi tubuh } \\
\text { yang benar }\end{array}$ & 8 & 20.0 & 32 & 80.0 \\
\hline $\mathrm{E}$ & Kendalikan cairan elektrolit pekat & 13 & 32.5 & 27 & 67.5 \\
\hline $\mathrm{F}$ & $\begin{array}{l}\text { Pastikan akurasi pemberian obat pada } \\
\text { pengalihan pelayanan }\end{array}$ & 7 & 17.5 & 33 & 82.5 \\
\hline G & Hindari salah kateter dan salah sambung slang & 7 & 17.5 & 33 & 82.5 \\
\hline $\mathrm{H}$ & Gunakan alat injeksi sekali pakai & 11 & 27.5 & 29 & 72.5 \\
\hline I & $\begin{array}{l}\text { Tindakan kebersihan tangan untuk pencegahan } \\
\text { infeksi nosokomial }\end{array}$ & 2 & 5.0 & 38 & 95.0 \\
\hline
\end{tabular}

Berdasarkan item keselamatan pasien di RS swasta Bantul responden yang menjawab baik paling banyak ada di item pernyataan tindakan kebersihan tangan untuk pencegahan infeksi nosocomial yaitu sebanyak 38 responden. Sedangkan responden yang menjawab tidak baik paling banyak ada di pernyataan pastikan identifikasi pasien yaitu sebanyak 19 responden.

Tabel 4. Keselamatan Pasien di RSU Swasta Bantul

\begin{tabular}{llll}
\hline $\begin{array}{l}\text { Kategori } \\
\text { pasien }\end{array}$ & Keseamatan & Frekuensi (N) & Persentase (\%) \\
\hline
\end{tabular}




\begin{tabular}{lll}
\hline Tidak baik & 14 & 35,0 \\
Baik & 26 & 65,0 \\
\hline Jumlah & 40 & 100 \\
\hline
\end{tabular}

3. Perbandingan Keselamatan Pasien di RSUD Bantul dengan Rumah Sakit Umum Swasta Bantul

Tabel 5. Perbandingan Keselamatan Pasien di RSUD Bantul dengan Rumah Sakit Umum Swasta Bantul

\begin{tabular}{llll}
\hline Perbandingan & Mean \pm SD & Z & P \\
\hline Perbandingan & & & \\
Keselamatan Pasien di & $171.8 \pm 9.00$ & & \\
RSUD Bantul dengan & & -0.714 & 0.475 \\
Rumah Sakit Umum & $174.2 \pm 7.19$ & & \\
Swasta Bantul & & & \\
\hline
\end{tabular}

Berdasarkan skor

keselamatan pasien di Keselamatan Pasien di RSUD didapatkan nilai rata-rata sebesar 171,8 dengan standar deviasi sebesar 900, sementara skor keselamatan pasien di Rumah Sakit Umum Swasta Bantul didapatkan nilai rata-rata sebesar 174,2 dengan standar deviasi sebesar 7,19. Hasil uji beda menggunakan Wilcoxon didapatkan sebesaar $-0,714$ dengan nilai probabilitas sebesar $0,475(\alpha>0,05)$ sehingga dinyatakan tidak ada perbedaan yang bermakna skor keselamatan pasien yang dilakukan di RSUD Bantul dengan Rumah Sakit Umum Swasta Bantul.

Hasil penelitian menemukan bahwa pelaksanaan patient safety di kedua rumah sakit yang menjadi tempat penelitian yaitu Rumah Sakit Umum Daerah Bantul dan Rumah Sakit Umum Swasta Bantul menemukan bahwa pelaksanaan patient safety di kedua rumah sakit tersebut telah berjalan dengan baik. Hanya saja pelaksanaan patient safety ini masih ditemukan beberapa item yang masih kurang seperti di Rumah Sakit Umum Daerah Bantul tentang pengendalian cairan elektrolit masih ditemukn $35,0 \%$ yang tidak baik, item keselamatan yang berkaitan dengan menghindari kesalahan kateter dan salah sambung selang masih ditemukan 37,5\% yang tidak baik.

Sementara itu pelaksanaan patient safety yang tidak baik juga ditemukan di rumah Sakit umum Swasta Bantul yaitu berkaitan dengan item memastikan identifikasi pasien masih ditemukan $47,5 \%$ yang tidak baik, dan item pengendalian cairan elektrolit pekat juga masih ditemukan $32,5 \%$ yang tidak baik. Hal itu sejalan dengan hasil penelitian Selleya C.B., yang judul "Hubungan Pengetahuan dan Sikap perawat Dengan pelaksanaan Keselamatan Pasien (Patient Safety) di Ruang Rawat Inap RSUD Liun Kendade Tahuna". menyatakan bahwa ada hubungan pengetahuan perawat dengan pelaksanaan keselamatan pasien (patient safety) di Ruang Rawat Inap RSUD Liun Kendage Tahuna, $p=0,014(\alpha<0,05)$. Ada hubungan sikap perawat dengan pelaksanaan keselamatan pasien (patient safety) di Ruang Rawat Inap RSUD Liun Kendage Tahuna, $\mathrm{p}=0,000(\alpha<0,05)$. 
Keselamatan pasien di Rumah Sakit adalah sistem pelayanan dalam suatu Rumah Sakit yang memberikan asuhan pasien menjadi lebih aman, termasuk di dalamnya mengukur risiko, identifikasi dan pengelolaan risiko terhadap pasien, analisa insiden, kemampuan untuk belajar \& menindaklanjuti insiden serta menerapkan solusi untuk mengurangi risiko. Keselamatan pasien merupakan suatu sistem yang sangat dibutuhkan mengingat saat ini banyak pasien yang dalam penanganannya sangat memprihatikan,dengan adanya sistem ini diharapkan dapat meminimalisir kesalahan dalam penanganan pasien baik pada pasien UGD, rawat inap maupun pada pasien poliklinik.

Pelaksanaan patient safety yang masih rendah ini tidak terlepas dari pemahaman responden yang masih rendah. Rendahnya pemahaman responden ini menjadi salah satu kendala dalam pelaksanaan patients safety. Hal tersebut dapat dilihat dari hasil penelitian bahwa budaya keselamatan yang rendah berhubungan dengan pelaksanaan pelayanan yang kurang baik Sementara responden dengan budaya keselamatan pasien yang tinggi akan melaksanakan pelayanan dengan baik.

Solusi yang diharapkan dari adaya kendala atau hambatan ini adalah pemberian pelatihan secara berkala kepada semua tenaga kesehatan di rumah sakit. Pelatihan dinyatakan sebagai bagian pendidikan yang menyangkit proses belajar untuk memperoleh dan meningkatkan keterampilan di luar system pendidikan yang berlaku dalam waktu yang relative singkat. Keterampilan yang dimaksud dalam hal ini adalah keterampilan dalam berbagai bentuk antara lain physical skill, intellectual skill, dan managerial skill. Jika dikaitkan dengan teori tersebut maka pelatihan yang dilakukan dalam penelitian ini harus berkaitn dengan peningkatan intellectual skill yang berhubungan dengan keselamatan pasien.

Diharapkan hasil penelitian ini dapat digunakan evaluasi pelaksanaan Patient Safety di lingkungan Rumah Sakit agar supaya dapat meningkatkan budaya patient safety yaitu adanya SOP, media monitoring dan evaluasi terhadap pelaksanaan patient safety yang dilakukan oleh tenaga medis sarana prasarana yang memadai, melakukan pelatihan tentang budaya keselamatan pasien secara berkesinambungan, serta sistem pelaporan setiap insiden terarah dan ditindaklanjuti.

\section{Simpulan}

Sebagian besar pelaksanaan patient safety di Rumah Sakit Umum Daerah Bantul pelaksanaan patient safety di Rumah Sakit Umum Swasta Bantul dalam kategori baik sehingga tidak terdapat perbedaan pelaksanaan patient safety di Rumah Sakit

\section{DAFTAR PUSTAKA}

Alimul Aziz. Riset keperawatan dan teknik penulisan ilmiah. Jakarta: Salemba Medika. 2003

Depkes RI. 2006. Panduan Nasional Keselamatan Pasien Rumah Sakit (Patient Safety), Jakarta: Ditjen P2M dan PLP, Jakarta. 
Departemen Pendidikan Nasional. 2001. Kamus Besar Bahasa Indonesia. Ed. 3. Jakarta: Balai Pustaka.

Endang Wahyati Yustina, 2012. Mengenal Hukum Rumah Sakit. Keni Media.

J.B. Suharjo B. Cahyono. 2005. Membangun Budaya

Keselamatan Pasien Dalam Praktek Kedokteran. Jogyakarta: Kanisius.

Joint Commision on Acreditation of Health Organization, Illinois, USA. 2001

KKP-RS. 2012. Workshop Keselamatan Pasien dan Manajemen Risiko Klinis. Hal. 1

Lia Mulyati dan Asep Sufyan. 2009. Pengembangan Budaya Patient Safety Dalam Praktik Keperawatan.

Notoatmodjo

Soekidjo.2005

Metodologi penelitian

kesehatan. Edisi revisi. Jakarta:

Rineka Cipta.

Notoatmodjo (2003) Pendidikan dan Perilaku Kesehatan. Jakarta : PT.Rineka Cipta

Peraturan Menteri Kesehatan Republik Indonesia Nomor 1691/Menkes /PER/VIII/2011, Tentang Keselamatan Pasien Rumah Sakit

Priyoto, Widyastuti. 2014. Kebutuhan Dasar Keselamatan Pasien. Graha Ilmu. Yogyakarta

Puji lestari, Maidin, dan Anggraeni.2013. Gambaran Budaya Keselamatan Pasien Oleh Perawat Dalam Melaksanakan Pelayanan di Instalasi Rawat Inap RSUP DR. Wahidin Sudirohusodo
Tahun 2013. Jurnal Media Kesehatan Masyarakat Indonesia Volume 10. Makasar. Universitas Hasanudin.

http://journal.unhas.ac.id/index .php/mkmi/article/view/484

Nomor halaman 01

Ronny Hanitijo Soemitro, 1988. Metodologi Penelitian Hukum dan Yurimetri, Ghalia Indonesia, Jakarta

Selleya C.B., Sinolungan, dan Hamel.2013.Hubungan

Pengetahuan dan Sikap perawat Dengan pelaksanaan Keselamatan Pasien (Patient Safety) di Ruang Rawat Inap RSUD Liun Kendade Tahun. Jurnal keperawatan Volume 01. Universitas Sam Ratulangi Fakultas Kedokteran pragram studi keperawatan: https://ejournal.unsrat.ac.id/ind ex.php/jkp/article/view/2237.

Nomor halaman 01

Setyarini dan

Herlina.2012.Kepatuhan

Perawat Melaksanakan

Standar Prosedur operasional - Pencegahan Pasien Resiko Jatuh di gedung Yosef 3 Dago dan Surya kencana Rumah Sakit Boromeus. Jurnal Kesehatan STIKes Santo Boromeus Volume 1. www.academia.edu/19879457/Jur nal_patient_safety_5. Nomor halaman 2

Sugiyono. Statistika untuk penelitin. Bandung: CV. Alfabeta. 2002

Undang-Undang Nomor 36 Tahun 2009 Tentang Kesehatan.

Undang-Undang Nomor 44 Tahun 2009 Tentang Rumah Sakit 
Jurnal Kebidanan, 7 (1), 2018, 39

WHO: 2004. World Alliance for

Patient Safety Forward

Programme, hal 6
WHO: World Alliance for Patient Safety. Forward Programme, 2004 